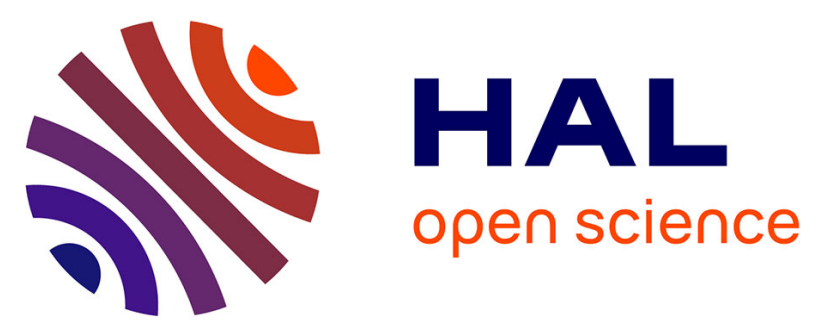

\title{
Saving energy by anticipating hot water production: identification of key points for an efficient statistical model integration
}

\author{
Yvan Denis, Frédéric Suard, Aurore Lomet, David Chèze
}

\section{- To cite this version:}

Yvan Denis, Frédéric Suard, Aurore Lomet, David Chèze. Saving energy by anticipating hot water production: identification of key points for an efficient statistical model integration. AI EDAM, 2019, 33 (02), pp.138-147. 10.1017/S0890060419000143 . cea-02571139

HAL Id: cea-02571139

https://hal-cea.archives-ouvertes.fr/cea-02571139

Submitted on 12 May 2020

HAL is a multi-disciplinary open access archive for the deposit and dissemination of scientific research documents, whether they are published or not. The documents may come from teaching and research institutions in France or abroad, or from public or private research centers.
L'archive ouverte pluridisciplinaire HAL, est destinée au dépôt et à la diffusion de documents scientifiques de niveau recherche, publiés ou non, émanant des établissements d'enseignement et de recherche français ou étrangers, des laboratoires publics ou privés. 


\section{Saving energy by anticipating hot water production: identification of key points for an efficient statistical model integration}

\author{
Yvan Denis \\ CEA, LIANES \\ INES 50 avenue du lac Léman \\ Technopôle Savoie Technolac \\ 73375 Le Bourget du Lac Cedex France \\ David Chèze \\ CEA, LSTB \\ INES 50 avenue du lac Léman \\ Technopôle Savoie Technolac \\ 73375 Le Bourget du Lac Cedex France
}

\author{
Frédéric Suard \\ CEA, LIANES \\ INES 50 avenue du lac Léman \\ Technopôle Savoie Technolac \\ 73375 Le Bourget du Lac Cedex France
}

\author{
Aurore Lomet \\ CEA, LIST \\ F-91191 Gif-sur-Yvette France
}

\begin{abstract}
This work aims to evaluate the energy savings that can be achieved in Domestic Hot Water (DHW) production using consumption forecasting through statistical modeling. It uses our forecast algorithm presented previously and aims at investigating how it can improve energy efficiency depending on the system configuration. Especially, the influence of the DHW production type used is evaluated as well as the water tank insulation. To that end, real consumption measurements are used for model training. Then simulations are carried on using TRNSYS software to calculate the total energy consumption of DHW production systems over one year. Simulations are also based on real consumption measurements for realistic results. To appraise the energy savings, we compared simulations that consider either no forecast (reactive control), perfect forecast (to estimate the control ability to consider forecast) and the forecast provided by our algorithm. The measurements and simulations are carried on 26 different but real dwellings to assess results variability. Several system configurations are also compared with varying thermal insulation indices for a complete benchmark of the approach so that an overall performance of system and anticipation could be evaluated.
\end{abstract}

\section{INTRODUCTION}

A recent study [1] showed that global energy consumption should be halved for European countries to meet 2050 ambitious objective of 75 to $90 \%$ reduction of greenhouse gases emissions. Energy saving is thus a major component of the effort that should be carried on for our future, along with the development of renewable energies.

Considering more precisely the residential sector, Space Heating (SH) and Domestic Hot Water (DHW) production represent a significant part of the total energy consumption, depending on the country and the geographical location. For example, heating, air conditioning and hot water production represent up to 65 and $77 \%$ of the total residential energy consumption in U.S. (source: EIA ${ }^{1}$ ) and in France (source: CEREN ${ }^{2}$ ) respectively, with 17.7 and $10 \%$ devoted to water heating.

To tackle this challenge, the two promising approaches currently in use are first the promotion of energy sobriety and also the energy efficiency enhancement through multiple ways as devices performance enhancement and demand side management. Based on previously published forecast algorithm (see [2]), the present study investigates the benefits that can be drawn from machine learning methods applied to energy consumption forecast to enhance the DHW production efficiency. In particular it analyses the adequacy between systems and provided forecast, with a specific focus on determining in which context forecasting can yield more energy savings and how much.

Forecasting domestic energy consumption using machine learning techniques has been extensively studied and summarized in some reviews comparing the different data based approaches [3]-[5]. Considering DHW forecast based on real data, Aydinalp et al. [6], Eynard et al. [7] and L. Gelaz̃anskas and K. A. A. Gamage [8] have proposed to use neural networks. Grey-box modeling approaches have been investigated by Bacher et al. [9] and Nielsen et al. [10] whereas non-homogenous Markov chains have been proposed by Sandels et al. [11]. Yet these approaches are time consuming and might not be appropriate for embedding into individual water heating systems.

Other methods based on lighter algorithms such as moving average have been proposed by Prud'Homme and Gillet [12]. However this approach has been shown to be less responsive to demand variation compared to our

\footnotetext{
${ }^{1}$ IEA, International Energy Agency, 2014. http://www.iea.org/.

${ }^{2}$ Centre d'études et de recherches économiques sur l'énergie, DONNÉES STATISTIQUES DU CEREN, 2014, http://www.ceren.fr/ stats
} 
algorithm [2]. Time series model such as ARMA has been proposed by Popescu et al. [13] but they focus on a bloc of 60 flats, which is more appropriate for district heating systems. This paper presents a method that uses ARIMA approach but focuses on individual dwellings which are more fluctuating than groups of residences. Moreover no assumption is done about the type of dwelling or characteristics and number of dwellers that are considered.

Applications of the DHW forecast to optimize DHW production have been presented in multiple studies [14] [16]. Although their results are encouraging, their models either assume the same deterministic profile for consumption and forecast (i.e. forecast are assumed perfect) or they focus on Economic Model Predictive Control (EMPC) (using the time dependent real price of electricity to save money, rather than focusing on saving energy) or also focus on district level rather than individual level.

Our approach consists in designing a lightweight algorithm that could be implemented in individual water heating devices to reduce the energy consumption. Forecasting DHW consumption allows heating only the required amount of water at the right time (just before water tapping), avoiding significant energy waste that can be observed in domestic water heater. It also enables a better dimensioning, reducing device's cost. The advantage of using such algorithm is that it is cheap to implement once developed compared with high efficiency materials, tank and heat production systems which production cost tends to increase along with the efficiency gain they provide.

Details and performance of the forecast algorithm have been published [2]. The aim of this current paper is rather focused on application and performance evaluation in realistic conditions. Two objectives are covered:

- Defining a methodology to compare traditional (reactive) heating systems with consumption forecast controlled ones (anticipative systems),

- Evaluate the benefits that can be drawn using consumption forecast and to which extent depending on heating systems characteristics.

Forecasting DHW consumption is only a part of our solution to the problematic of reducing energy consumption. In this paper, we analyze to which extent the use of consumption forecast can enable saving energy. In particular, the influence of the type of DHW production system used is evaluated as well as some main parameters like the insulation of the water tank. To achieve this, we use TRNSYS $^{1}$ simulation software to model the different systems in combination with our forecast algorithm. Simulations and forecast computations are based on real measurements coming from several dwellings. Then the difference of heating systems performance is evaluated by comparing simulation results. Three different systems configurations are tested, with a wide range of complexity

\footnotetext{
${ }^{1}$ See http://www.trnsys.com/
}

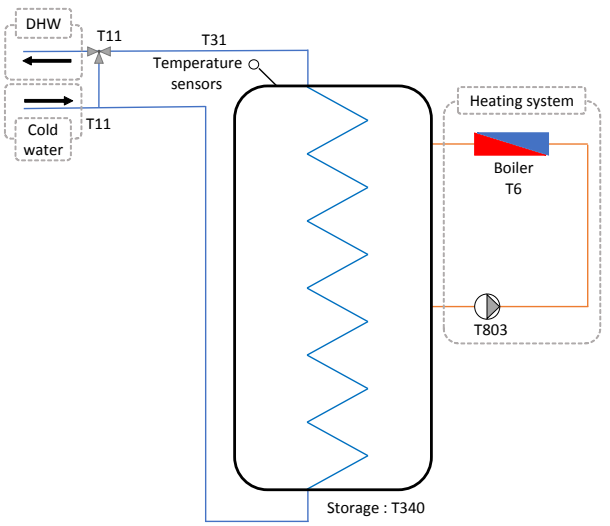

Figure 1: Heat production system with electrical resistance

and efficiency to evaluate precisely the benefits of this approach depending on the used technology.

This report starts by the description of the methodology. The heating systems are first explained. Then a brief description of the measurements used as input to our model and to the simulator is provided. The next part details TRNSYS simulations setups. A description of the building stages of the forecast algorithm is then explained. Results from the forecast algorithm and simulations are provided in section III, along with a detailed analysis, explanations and interpretations. A synthesis of the relevant conclusions is provided at the end of the paper.

\section{EXPERIMENTAL PROCEDURE}

To evaluate the benefits that can be drawn from using energy needs forecast in water heating systems, simulations are ran considering different systems over one year based on real consumption measurements from different dwellings. Each experimental case is simulated with and without forecast. This approach allows to determine the benefits of forecasting depending on the type of system considered while ensuring that the result does not depend on the load profile used as simulation input.

\section{A. Considered systems}

Three different systems are considered for this study spawning a large range of complexity:

- Configuration 1 consists of a $763 \mathrm{~L}$ stratified water tank connected to an electric (resistive) heating system (see figure 1).

- Configuration 2 uses the same water tank powered by a Heat Pump (HP).

- Configuration 3 is identical to configuration 2 with an additional Solar Thermal Collector (STC) as an auxiliary power source (see figure 2).

Note that in figures 2 and 1 , Ti refers to the component of type $i$ used in TRNSYS software. 


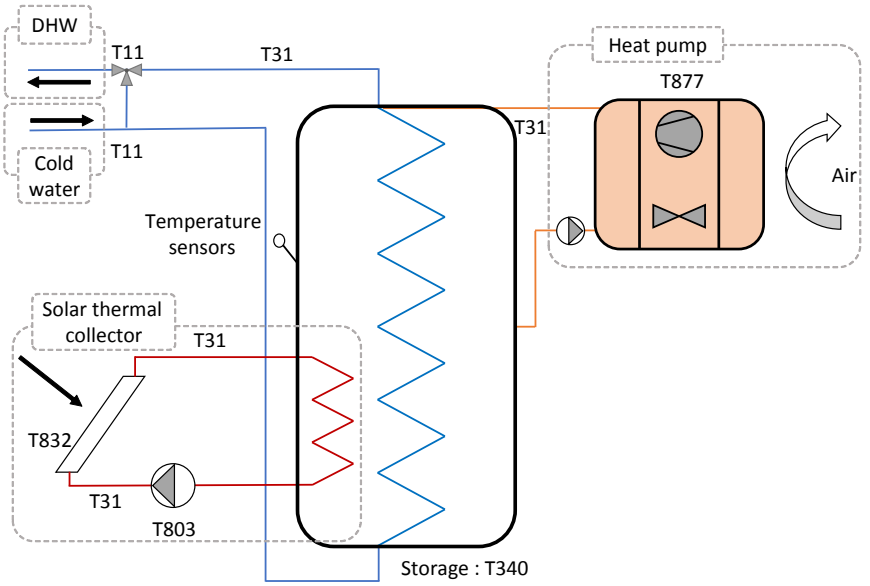

Figure 2: Heat production system with solar thermal collector and heat pump

\section{B. Description of real consumption measurement data sets}

A total of 26 data sets are used to perform forecast and simulation. These data are issued from 3 different locations in France and Sweden and have been gathered during CombiSol European project ${ }^{2}$ and French SCHEFF $^{3}$ project. These data sets will be denoted A, B and C respectively and are presented in Table I. Each data set measures the hot water needs in liters for a real domestic dwelling. DHW consumption measurements have been performed every 6 minutes. Missing values generally concern less than $5 \%$ of the data. Linear interpolation has been performed if the time window of missing data is shorter than 3 hours to complete the time series. Otherwise, the time window is not considered for the analysis.

Table I: List of measured dwelling grouped by project

\begin{tabular}{|l|l|l|l|}
\hline Name & Location & $\begin{array}{l}\text { Number of } \\
\text { dwelling } \\
\text { measured }\end{array}$ & $\begin{array}{l}\text { Period of } \\
\text { measurements }\end{array}$ \\
\hline $\mathrm{A}$ & France & 8 & $2010-2011$ \\
\hline $\mathrm{B}$ & Sweden & 8 & $2007-2009$ \\
\hline $\mathrm{C}$ & France & 10 & $2007-2009$ \\
\hline
\end{tabular}

\section{Description of the simulation setup}

All the three TRNSYS setups are derived from the core simulation setup developed for MacSheep European project provided by D. Chèze et al. [17]. This setup is the most complete and energetically efficient one. The heating system comprises a heat pump connected to a vertical borehole heat exchanger as well as a STC. These devices are connected to a stratified water tank through double ports or heat exchangers from which is drawn hot water

\footnotetext{
${ }^{2}$ More informations available at: https://ec.europa.eu/energy/intelligent/projects/en/projects/combiso

${ }^{3}$ ADEME (http://www.ademe.fr/) project SCHEFF : Solaire collectif à haute efficacité
}

for domestic use. The total volume of the tank is $750 \mathrm{~L}$. Since a STC can provide a large part of the required DHW in summer almost for free (only a pump to flow water through the collector is required), limited energy savings are expected in this configuration. However this kind of system is not extensively used today. Thus, a second system has been designed without STC. Except the STC, this setup is perfectly equivalent to the first one. Since these two systems are not representative of what can be found as DHW heating systems, a third system has been simulated which consists of the same water tank connected to an electric water heater. Electric heater is simulated thanks to type 6 unit of TRNSYS with a maximum heating rate of $8000 \mathrm{~kJ} / \mathrm{h}$ and a perfect efficiency. Although this efficiency is not relevant, it does not call into question conclusions since they will be based on relative savings considering the same system parameters with and without forecast. There are two different control strategies according to whether or not forecast is taken into account, i.e. reactive and anticipative. If the forecast is not taken into account, the control strategy is a traditional one, in other words the water is heated at the set point temperature $\left(50^{\circ} \mathrm{C}\right.$ in this case, as recommended by the European and United States institutions) all the time. This is achieved using a thermostat with a hysteresis of $\pm 2{ }^{\circ} \mathrm{C}$. In the case where we account for forecast, the available energy in the tank at time $t$ is compared to the forecast quantity of energy that will be consumed during the next coming hour. If sufficient energy is stored, the heating system remains off or is switched on otherwise. A hysteresis controller is also added in this case with a dead band of at least the equivalent of 10 liters of hot water or $10 \%$ of the required energy for the next hour.

\section{Description of the forecast algorithm}

The detail of the algorithm can be found in [2]. However we briefly describe it here for convenience. The procedure is broken down in steps that are illustrated in figure 3 where $Y(d)$ and $F(d)$ are the measured and forecast daily consumption respectively, $y(t)$ and $f(t)$ are the measured and forecast intra-day consumption profiles respectively, $d$ is the day index and $t$ is the time index within a day (in hours), $G$ is the pool of mean intra-day consumption profiles, $N_{t r a}$ and $N_{\text {for }}$ are the number of days used for training and forecasting time series respectively.

1) ARIMA modeling of daily consumption: To forecast DHW consumption the algorithm only needs the record of the 3 last months of consumption $\left(Y_{d} \forall d \in\left[-N_{t r a}+1: 0\right]\right.$ in figure 3). The input for the self-learning process is thus a discrete time series of consumption in liters. The total consumption per day is modeled using an ARIMA function [18]. A training window of $N_{t r a}=84$ days is used to estimate the values of coefficients during the learning stage. This is the step one in figure 3. Forecast is performed 


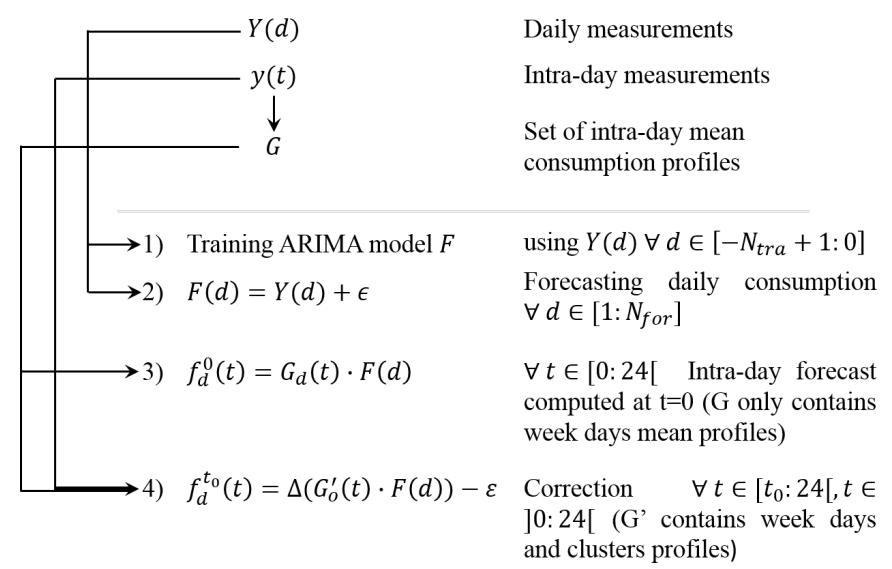

Figure 3: Algorithm scheme

over a one year period that follows the training window. The formula is shown in equations 1 and 2:

$$
\begin{gathered}
X_{t}=\sum_{i} \varphi_{i} X_{t-i}+\sum_{i} \theta_{i} \epsilon_{t-i}+\epsilon_{t}, \\
\forall t \in \mathbb{Z}, X_{t}=\nabla^{d} Y_{t},
\end{gathered}
$$

where $Y_{t}$ is the forecast, the parameters $\varphi_{i}$ and $\theta_{i}$ are linear coefficients, $\epsilon_{t}$ is a white noise, $i \in\{1,2,7\}$ and $d$ is the degree of differencing. This auto regressive part is formed by a linear combination of the consumption of the two previous days and the same day of the previous week (denoted by $i \in\{1,2,7\}$ ). The moving average part is also based on the error made on these days. This form of the model is fixed for all dwellings. This allows faster computation for model training, which is a great asset for embedding into the water tank. This form as been chosen so that it fits best the 26 dwellings. However the differentiation degree is calculated independently for each dwelling in order to build the model on a stationary time series. This is the second step in figure 3 .

2) Intra day consumption modeling: After forecasting the daily consumption, intra-day cumulative consumption is forecast. The method consist in building a set of normalized and representative daily load curves. Then the cumulative consumption within each day is assumed to conform to the most appropriate load curve picked from curve set. For each day, the final forecast is obtained by scaling the normalized curve with the ARIMA forecast.

A first set of curves is constructed based on the day of the week. That is, every load curves of the same day of the week measured during the training test are gathered. The representative curve is then obtained by computing the average of the curves. This is the third step in figure 3. As an example intra-day profiles for dwelling A1 are shown in figure 4.

Each average curve is then modeled using a sum of sigmoid functions. It enables having smoother profiles and

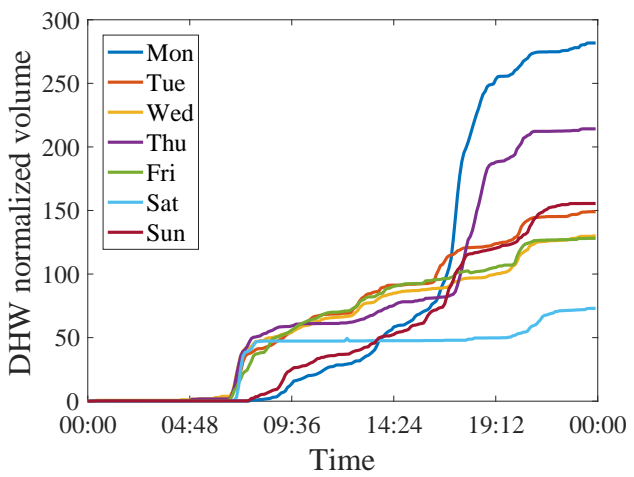

Figure 4: Intra-day DHW consumption profile of dwelling A1 for each day of the week.

requires less memory for embedding. Combining ARIMA forecast with the corresponding week day average cumulative consumption yields a first continuous forecast for the entire year. This is the fourth step in figure 3 .

3) On line correction of the forecast every hour: In order to have a better forecast accuracy, the profile is corrected every hour, at time $t$, based on the observed real consumption of the day. The correction consists first in checking if a better load profile can be found considering the load curve measured since the beginning of the day.

The most adequate load profile is found among an extended set of curves, build using the previous set of curves (average week day load profiles) and a set of average curves of load profiles clusters. Clusters of profiles are built using the Silhouette approach [19] that groups together the curves which are the most similar to each other. This method is applied on all the intra-day cumulative consumptions. A flat curve is added to the extended set of curves corresponding to the days with no DHW consumption. This is a particular case that should be accounted for since it is not unlikely (e.g. during vacation) nor frequent but accounting for it properly can enable large savings.

At each correction step, the best load profile is found as the highest scalar product between the measured load curve and each curve of the set. Scalar product has been preferred to other metric since it yields better results when building profile clusters. To get the forecast cumulative consumption for the rest of the day, this curve is scaled to match the current consumption (at time $t$ ) and the cumulative consumption forecast by ARIMA at the end of the day. As the time passes, ARIMA weights less on the scaling of the curve. Indeed, when time reaches closer to the end of the day, the actual consumption becomes more relevant as the daily consumption forecast than ARIMA forecast. This time dependent weight is implemented by linearly weighting ARIMA forecast. The weight equals 1 and 0 at the beginning and the end of the day respectively. This is the fifth step in figure 3 . 


\section{E. Performance comparison protocol}

To compare the performance yield by each experiment, the energy savings after one year of consumption are calculated. Energy savings are the difference of the electrical energy consumed by the system accounting for forecast (anticipative system) or not (reactive system, which is considered as the baseline). Further results (figure 5,6a, 9 and 10) are shown in relative scale. These relative energy savings are computed using the formula shown in 4, where $E_{s}$ is the energy saved, $E_{r}$ and $E_{a}$ are the energy consumed by reactive an anticipative systems respectively.

$$
E_{s}=\frac{\left(E_{r}-E_{a}\right)}{E_{r}} 100
$$

In order to have a relevant comparison between experiments, the discomfort due to missing hot water should be taken into account. To do so, energetic penalties are added to the total electrical energy consumption of the system whenever hot water is missing, according to the standard penalty function calculation given by the IEA [20]. The penalty is calculated as the missing energy multiplied by a yield factor of 1.5. The equation is recall here for convenience:

$$
E_{\text {pen }}=1.5 \cdot E_{\text {miss }}
$$

where $E_{p e n}$ is the penalty energy and $E_{\text {miss }}$ is the total energy that had not been delivered due to missing hot water in the tank. This penalty function can be considered has the extra energy that would be consumed by a hypothetical auxiliary system to compensate for the missing heat.

\section{RESUlts AND DISCUSSIONS}

\section{A. Energy savings}

Energy savings made using forecasts are shown in figure 5 and 6 using the perfect forecast and the ARIMA forecast obtained with our algorithm respectively. Perfect algorithm are used here to show the upper limit in terms of energy savings, no matter how precise the forecast is. It is not an absolute upper limit since it does not address the issue of forecast and system control interfacing. For each system configuration, all the 26 profiles have been used to simulate savings. Overall savings are comprised between -3.6 and $17.4 \%$ of the total energy consumed. These figures show that the overall saving amount depends on the system but also on the dwelling (and thus the dwellers habits) since boxes spread is not negligible.

The results also suggest that a solar collector reduces the effectiveness of the technique. Indeed, in summer, a significant part of the energy is provided by the solar collector almost for free (neglecting the energy for pump). Considering systems without solar collector, heat is provided thanks to heat pump or resistive devices that are less efficient. Figures 7 and 8 illustrate that on a particular dwelling. The figure 7 shows that in summer, almost no

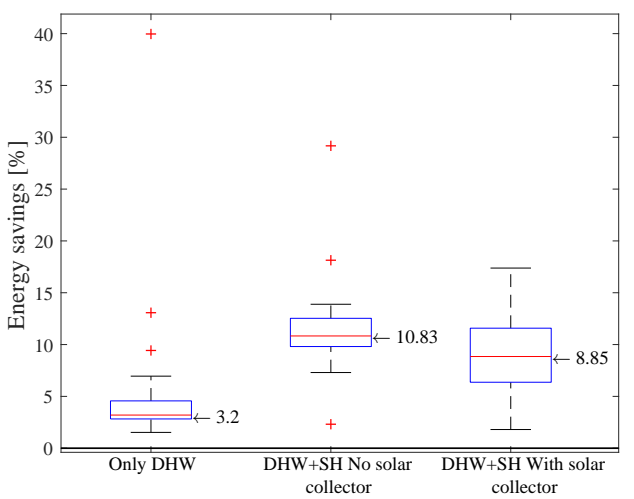

Figure 5: Relative energy savings using the perfect forecast on the 26 dwellings depending on the considered system

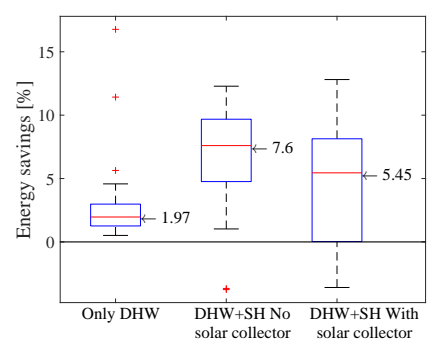

(a)

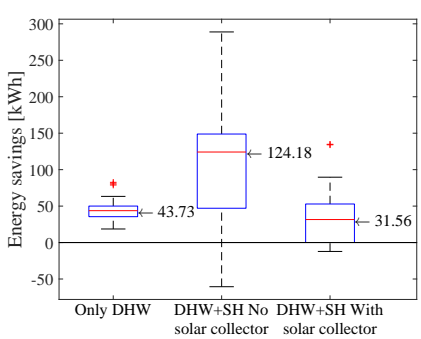

(b)
Figure 6: Relative (a) and absolute (b) energy savings using ARIMA forecast on the 26 dwellings depending on the considered system

energy comes from HP when STC is in operation. The consequence on energy saving is shown in figure 8. No extra savings are achieved during the summer if STC is working while savings steadily increases in the other case. Even though the efficiency of the resistive system is lower than the others, the energy gains observed using forecast are less important than the case of HP systems. We could expect the gain to be greater (at least) since the production system consumes more energy normally. Figure 5 and 6 show that this intuition is neither verifyed in relative scale nor in absolute. The explanation is that, since the production behavior is very different, the thermal inertia is different, thus, the way the system accounts for forecasts might be less appropriate and yields less savings.

More precisely, in this case, the pipes inlet and outlet positions of the heat production loop and the temperature sensor position are responsible for the thermal inertia discrepancy between systems. These positions are summarized in table II and can be observed in figures 2 and 1. The consequence is that the configuration 1 has short operating cycles that heat a smaller volume of water than configuration 2-3 (the sensor being placed higher). Thus, if 


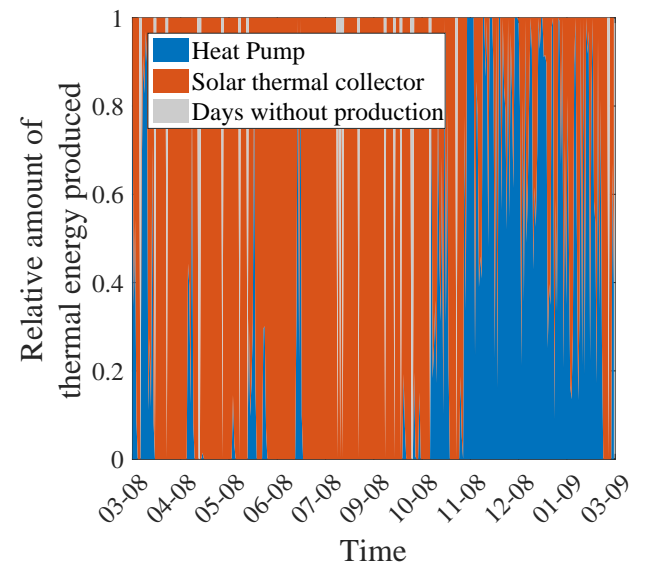

Figure 7: Relative contribution of each source to the thermal energy produced each day

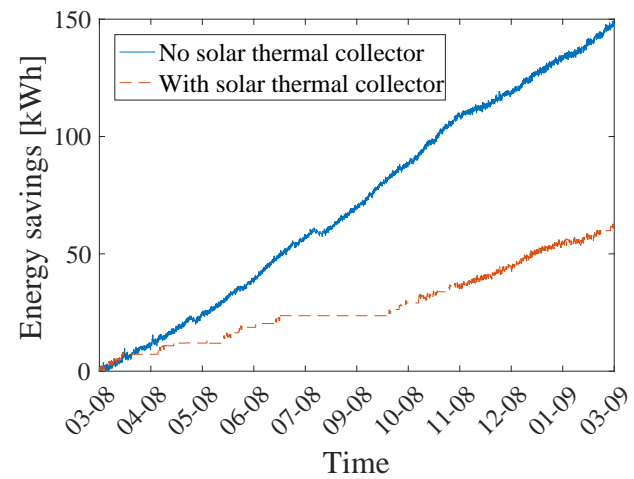

Figure 8: Cumulated savings using the HP system with and without STC (configurations 2 and 3 )

DHW is regularly tapped, the average exergy of the tank is lower and so are the thermal dissipation compared to configuration 2-3. This is why energy savings are lower in configuration 1. However this does not hold anymore if there are long periods of absence (greater than 10 days). In this case, which occurs sparsely in our data, without forecast, configuration 1 ends up by heating the whole tank (since DHW is not tapped) and energy losses become as high as in configuration 2. The energy yield being lower in configuration 1, the anticipative system allows larger savings since it enables shutting down the boiler when no DHW is tapped during the day.

The main result to retain is that the characteristics of the boiler can have an impact on how much savings the anticipative system can yield. The algorithm can be tuned to be more efficiently adapted to the boiler. For example forecast horizon can be extended or shrunk to adapt to the effective inertia of the boiler and the amplitude of consumption peaks.

The effect of thermal insulation of the tank has been studied as well. The reference system has a thermal loss
Table II: Relative position of sensor and pipe/tank connections ( 1 and 0 are the top and the bottom of the tank respectively)

\begin{tabular}{|l|l|l|l|}
\hline & sensor & inlet & outlet \\
\hline Configuration 1 & 1 & 0.85 & 0.47 \\
\hline Configuration 2-3 & 0.65 & 1 & 0.49 \\
\hline
\end{tabular}

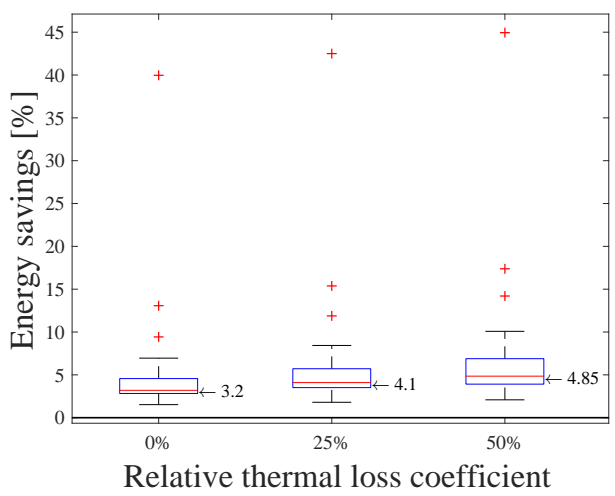

Figure 9: Relative energy savings using perfect forecast depending on insulation, considering only configuration 1 (system with resistive heating device). Insulation varies from nominal value $(0 \%)$ down to $50 \%$ less efficiency

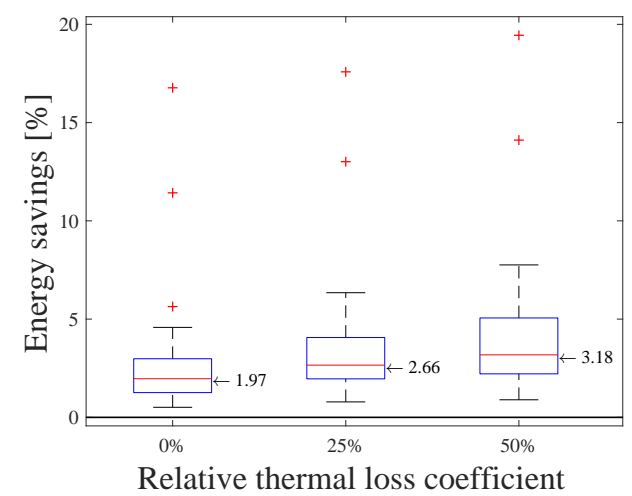

Figure 10: Relative energy savings using ARIMA forecast depending on insulation, considering system with resistive heating device. Insulation varies from nominal value $(0 \%)$ down to $50 \%$ less efficiency

coefficient of 1.08, 10.12 and $2.41 \mathrm{~kJ} /(\mathrm{h} . \mathrm{K})$ at the top, side and bottom of the tank respectively. More information can be found in [21]. Figure 9 and 10 show results obtained with the 26 dwellings simulated with differents thermal insulations. As a results, a poorer insulation allow more savings using the forecast. Indeed, if the tank is well insulated, hot water can be stored longer without suffering from extra dissipation. Thus forecasting the consumption becomes less relevant in terms of energy gain.

Figures 9 and 10 show that relative savings using consumption forecast are increased by $52 \%$ of the baseline 
value when the insulation is halved. In other words, the relative energy savings increase by 1.65 . The effects of the insulation coefficient are slightly exacerbated using ARIMA (up to $61 \%$ increase of the baseline value of relative energy saving when the insulation is halved) but the difference might not be significant (relative energy savings increases up to 1.21). So an anticipative strategy is much more adapted with higher energy loss.

\section{B. Performance of the algorithm and energetic efficiency}

1) Relation between model accuracy and energy savings: All previous results showed that energy savings depend strongly on the system. It does also depend on the prediction accuracy since using exact forecast yields better results than using ARIMA in figure 9 and 10. To gain a better insight into the relations between forecast error and energy savings, the energy savings discrepancies observed using ARIMA and perfect forecast are plotted in figure 11. Energy gain using perfect forecast is significantly better than using ARIMA forecast. Thus a better accuracy of the model can still improve the energy savings up to $3.8 \%$ in average.

The model Mean Error (ME) is computed over each simulated year and plotted against energy savings in figure 12, for each simulated configuration of system and dwelling, using ARIMA and perfect forecast. Errors are computed on the cumulative consumption forecast for the next hour using formulas 5 ,

$$
M E=\frac{1}{n} \sum_{t=1}^{n}\left(F_{t}-Y_{t}\right),
$$

where $Y_{t}$ and $F_{t}$ denote observations and forecasts respectively with $t$ covering the simulated year. Figure 12 shows that the ME is homogeneously spread around 0 and that a high negative or positive ME value does not imply lower savings. However we have seen that the difference between savings using perfect forecast and ARIMA is significantly positive. The conclusion is thus threefold:

- Lower forecast accuracy reduces energy savings.

- The system type affects the yield as much as the forecast accuracy.

- ME indicator is not well suited to assess the forecast accuracy that drives energy savings.

Considering the interface between forecasts and the control system, the implemented strategy consists in evaluating at each time step the available energy stored in the tank and comparing it with the cumulative consumption forecast over an horizon of $H$ hours. The stored energy is adjusted whenever some is missing by turning the production system on. Available energy is computed using 4 sensors spread along the top half section of the tank. If the stored water is below $T_{m} i n$, then its energy is not taken into account, since this water would not be hot enough if drawn. In our case $H=1$ hour and $T_{m} i n=48^{\circ} C$ ). However, depending on the thermal inertia of the system, these

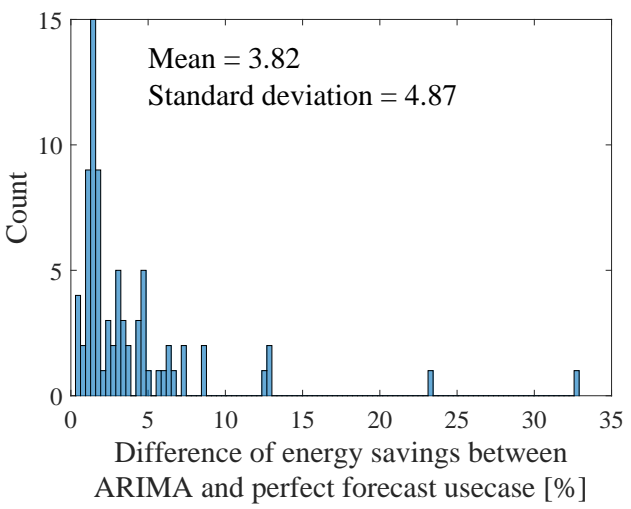

Figure 11: Distribution of energy savings discrepancies observed using perfect forecast and ARIMA, calculated over the 26 dwellings with the different configurations

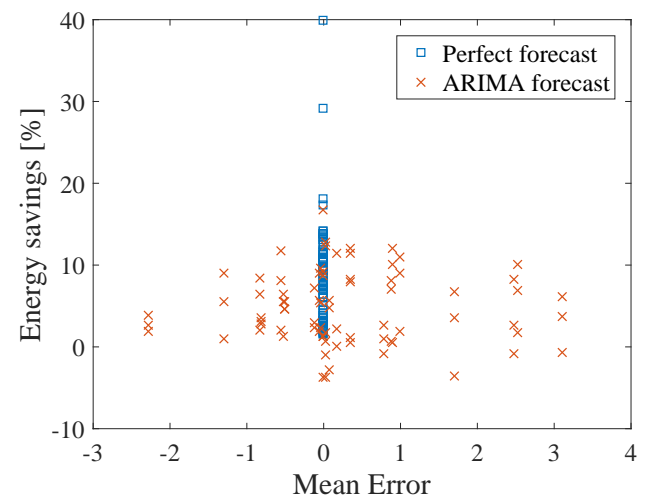

Figure 12: Energy savings against model mean error

parameters could be modified and improve or degrade the energy gain obtained using forecast.

2) Effect of concept drift on model accuracy and energy savings: A statistical model trained on a particular data set is suited to forecast consumption of the dwelling from which the training set has been measured. However nothing ensure that this model would be fitted for another dwelling since it is occupied by other dwellers with different habits. Moreover within the same dwelling, dwellers can change with time, compromising the fitness of the model. This problem is referred as concept drift. To investigate the extend of the error caused by concept drift, models trained on specific dwellings have been used to forecast other dwellings consumptions. Figure 13 shows the forecasts obtained for dwelling D6 using the models calibrated using DHW consumption of dwelling D6 and D9. The model trained with dwelling D6 is representative of the different models trained with the 26 dwellings (ARIMA coefficients are the closest to coefficients means). Error observed using model calibrated on D6 to forecast dwelling D9 consumptions is representative of the errors observed using the same model to forecast all the other 


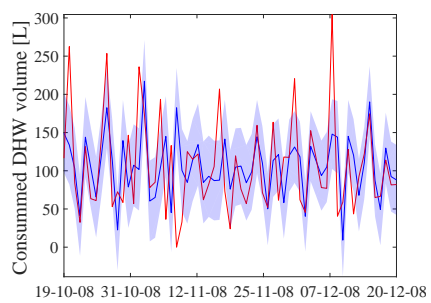

(a)

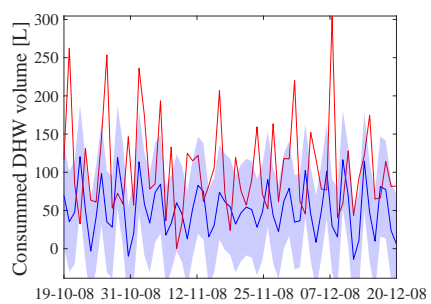

(c)

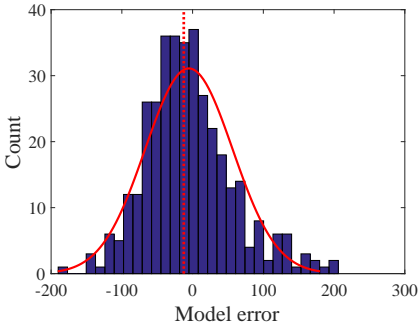

(b)

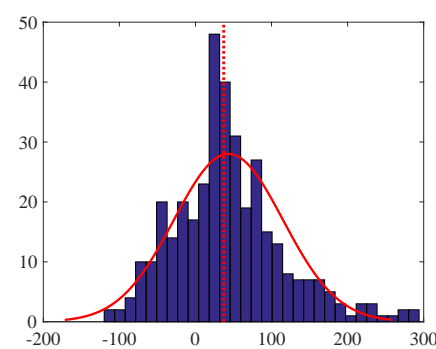

(d)
Figure 13: Dwelling D6 DHW consumption measured

(red lines) and forecast (blue lines) using model calibrated on D6 (a) and D9 (c). Histogram of model error $(Y(d)-F(d))$ with model calibrated on D6 (b) and D9 (d).

dwellings. The figure shows that concept drift can add a serious bias in the forecast. In this case, the forecast is systematically underestimated. Even though we have seen that large ME and MAE does not necessarily lead to lower energy savings, the problem of concept drift should be kept in mind and dealt with.

\section{Discussions and guidelines}

Improving the energy efficiency of an individual DHW production system using forecast is a challenging task for many reasons. The first challenge not in the scope of this study is to use efficiently a statistical model for DHW forecast through the control. For exemple, we consider a single dwelling rather than a full district or a town (i.e. for the case of urban heating network) which is easier to forecast thanks to the aggregation of consumptions. Moreover DHW consumption fluctuate over time and is hard to predict since it does not necessarily depend on external factor like external temperature [2] compared to space heating production. This has been studied and published in previous papers [2] and [22].

However, we focus here on considerations about model embedding into production systems. The study shed some light about the difficulties of saving energy within anticipative systems (i.e. that uses forecast). First of all, anticipative systems yields to greater savings using tank with poorer insulation than our study case. Second, there is no direct relationship between initial efficiency of the system and the energy gain that one can expect using forecast. In particular, using STC brings energy to the tank during summer almost for free, thus restricting the economies made using forecast compared with systems without STC. However the energy gains are even more restricted considering a simple resistive system to produce DHW, which efficiency is lower than HP systems with and without STC. This has been attributed to the compatibility between forecasts and the system, through the control strategy and the system's characteristics itself. For example, the position of the pipes inlet and outlet and the thermal sensor have been pointed out as being responsible for shorter heating cycles in the system configuration 1 leading to lower exergy stored and thus less dissipation for most of the dwellings. Thus the production system characteristics have a large impact on the energy savings.

Finally the energy gain also strongly depends on the dwelling considered and dwellers habits. Thus no pledge about the saving amount can be held without knowing the DHW production system and the dwellers habits, with the strategy we used to interface forecasts and the control system.

\section{Conclusion and Perspectives}

This paper aims at investigating whether forecasting DHW consumption can lead to significant energy savings in individual scale DHW production system. It focuses on evaluating the compatibility between the consumption forecast model and the DHW production system. To achieve this, a large set of simulations has been carried on 26 real and different dwellings, considering 3 different systems for each, one whose tank insulation parameter ranges over three levels. Energy savings have been evaluated between -3.6 and $12.8 \%$ depending on the experimental case. This has been shown using a time series based algorithm to forecast consumption and TRNSYS tool to simulate the system and the DHW demand. Real consumptions have been used as input to the simulator and to train the forecasting model, in order to have statistical estimation of the energy savings.

The main conclusions of this study are the following:

- The percentage of energy saved depends on:

- the dwellers and their habits,

- the characteristics of the DHW production system (like yield and tank insulation),

- the forecast accuracy.

- ME and MAE are not well suited to estimate the energy efficiency gain of the anticipative system compared with the reactive one.

- Concept drift can induce a large bias in the forecast and should be properly addressed.

As a perspective, an adaptive forecast model that deal with concept drift and optimizes the interface with the control strategy will be considered to challenge the context changing. 


\section{ACKNOWLEDGMENT}

Some data and algorithmic resources used in this work come from output materials of the European Union's Seventh Framework Program FP7/2007-2011 under grant agreement n²82825 - Acronym MacSheep.

\section{REFERENCES}

[1] NégaWatt, "Projet "europe-territoires": Transition(s) énergétique(s) en europe : analyse comparative de scénario, de leur application territoriale et de leurs impacts socio-économiques." Internet, march 2016.

[2] A. Lomet, F. Suard, and D. Chèze, "Statistical modeling for real domestic hot water consumption forecasting," Energy Procedia, vol. 70 , pp. 379-387, 2015.

[3] L. Suganthi and A. A. Samuel, "Energy models for demand forecasting - a review," Renewable and Sustainable Energy Reviews, vol. 16, no. 2, pp. 1223-1240, 2012.

[4] C. Deb, F. Zhang, J. Yang, S. E. Lee, and K. W. Shah, "A review on time series forecasting techniques for building energy consumption," Renewable and Sustainable Energy Reviews, vol. 74, pp. 902-924, 2017.

[5] L. G. Swan, V. I. Ugursal, and I. Beausoleil-Morrison, "Occupant related household energy consumption in canada: Estimation using a bottom-up neural-network technique," Energy and Buildings, vol. 43, no. 2, pp. 326-337, 2011.

[6] M. Aydinalp, V. Ismet Ugursal, and A. S. Fung, "Modeling of the space and domestic hot-water heating energy-consumption in the residential sector using neural networks," Applied Energy, vol. 79, no. 2, pp. 159-178, 2004.

[7] J. Eynard, S. Grieu, and M. Polit, "Wavelet-based multiresolution analysis and artificial neural networks for forecasting temperature and thermal power consumption," Engineering Applications of Artificial Intelligence, vol. 24, no. 3, pp. 501-516, 2011.

[8] L. Gelažanskas and K. A. Gamage, "Forecasting hot water consumption in dwellings using artificial neural networks," in Power Engineering, Energy and Electrical Drives (POWERENG), 2015 IEEE 5th International Conference on, pp. 410-415, IEEE, 2015.

[9] P. Bacher, H. Madsen, H. A. Nielsen, and B. Perers, "Shortterm heat load forecasting for single family houses," Energy and Buildings, 2013.

[10] H. A. Nielsen and H. Madsen, "Modelling the heat consumption in district heating systems using a grey-box approach," Energy and Buildings, vol. 38, no. 1, pp. 63-71, 2006.

[11] C. Sandels, J. Widén, and L. Nordström, "Forecasting household consumer electricity load profiles with a combined physical and behavioral approach," Applied Energy, vol. 131, pp. 267-278, 2014.

[12] T. Prud homme and D. Gillet, "Advanced control strategy of a solar domestic hot water system with a segmented auxiliary heater," Energy and buildings, vol. 33, no. 5, pp. 463-475, 2001.

[13] D. Popescu and E. Serban, "Simulation of domestic hot-water consumption using time-series models," in Proceedings of the 6th IASME/WSEAS International Conference on Heat Transfer, Thermal Engineering and Environment, Rhodes, Greece, pp. 20$22,2008$.

[14] F. Sossan, A. M. Kosek, S. Martinenas, M. Marinelli, and H. Bindner, "Scheduling of domestic water heater power demand for maximizing pv self-consumption using model predictive control," in Innovative Smart Grid Technologies Europe (ISGT EUROPE), 2013 4th IEEE/PES, pp. 1-5, IEEE, 2013.

[15] R. Halvgaard, P. Bacher, B. Perers, E. Andersen, S. Furbo, J. B. Jørgensen, N. K. Poulsen, and H. Madsen, "Model predictive control for a smart solar tank based on weather and consumption forecasts," Energy Procedia, vol. 30, pp. 270-278, 2012.

[16] J. Eynard, S. Grieu, and M. Polit, "Predictive control and thermal energy storage for optimizing a multi-energy district boiler," Journal of Process Control, vol. 22, no. 7, pp. 1246$1255,2012$.
[17] D. Chèze, C. Bales, J. Betak, M. Broum, J. Heier, A. Heinz, H. Franz, Q. Hamp, and S. Poppi, "Final report on control strategies, fault detection and on-line diagnosis in wp6deliverable 6.4: Macsheep-new materials and control for a next generation of compact combined solar and heat pump systems with boosted energetic and exergetic performance," 2015.

[18] G. E. Box, G. M. Jenkins, and G. C. Reinsel, Time series analysis: forecasting and control. John Wiley \& Sons, 2013.

[19] P. J. Rousseeuw, "Silhouettes: a graphical aid to the interpretation and validation of cluster analysis," Journal of computational and applied mathematics, vol. 20, pp. 53-65, 1987.

[20] M. Haller, R. Dott, J. Ruschenburg, F. Ochs, and J. Bony, "The reference framework for system simulations of the iea shc task 44/hpp annex 38 part a: General simulation boundary conditions," International Energy Agency, A technical report of subtask C Report C1 Part A, 2013.

[21] C. Bales, J. Betak, M. Broum, D. Chèze, G. Cuvillier, R. Haberl, B. Hafner, M. Y. Haller, Q. Hamp, A. Heinz, et al., "Optimized solar and heat pump systems, components and dimensioning,"

[22] A. Lomet, Y. Denis, F. Suard, and D. Chèze, "Statistical modeling to forecast the domestic hot water consumption," Energy and Building, To be published. 